\title{
A representationalist reading of Kantian intuitions
}

\author{
Ayoob Shahmoradi ${ }^{1}$ (if
}

Received: 22 March 2018 / Accepted: 1 April 2019

(c) Springer Nature B.V. 2019

\begin{abstract}
There are passages in Kant's writings according to which empirical intuitions have to be (a) singular, (b) object-dependent, and (c) immediate. It has also been argued that empirical intuitions (d) are not truth-apt, and (e) need to provide the subject with a proof of the possibility of the cognized object. Having relied on one or another of the a-e constraints, the naïve realist readers of Kant have argued that it is not possible for empirical intuitions to be representations. Instead they have argued for a relationalist reading of empirical intuitions in terms of an acquaintance relation between the subject and the intuited object. For the sake of argument, I will grant the naïve realist reader of Kant that empirical intuitions should satisfy all the (a)-(e) constraints. Nevertheless, by incorporating these constraints, one by one, into a representationalist theory of empirical intuitions, I will show that not only doesn't a naïve realist reading of empirical intuitions follow, but also that the naïve realist has hastily overlooked a range of perfectly representationalist readings of intuitions available to Kant and his representationalist allies. On the positive side, I will argue that there is an extra constraint on intuitions-i.e., that givenness does not require presence to consciousness - that directly goes against any naïve realist account of intuitions.
\end{abstract}

Keywords Kant · Empirical intuitions $\cdot$ Representationalism · Naïve realism

\section{Introduction}

I begin with two preliminaries. The first one (Sect. 2.1) gives a sketch of the contemporary philosophy of perception and where the two main parties, i.e., representationalists and naïve realists stand. The next, very short, preliminary (Sect. 2.2) settles some Kantian terminology that will be crucial for understanding the arguments that will follow. In particular I will discuss Kant's notion of 'empirical intuition'. Section 3 explains why people have taken Kant to be endorsing an object-dependent view of intuitions.

\footnotetext{
Ayoob Shahmoradi

ayoob@ucsd.edu

1 University of California, San Diego, USA
} 
In Sect. 4, I present different versions of representationalism that welcome Kant's object-dependent intuitions. Section 5 shows why not only isn't the immediacy of intuitions a ground against the representationalist reading of intuitions but also how it is happily sheltered under such an account. Section 6 shows how intuitions as representations, whether propositional or not, need not be truth-apt. I will also explain how the unity of a proposition could be obtained independently of the understanding. Section 7 explains how an intuitions as a representation provides a proof of the possibility of the cognized object. Section 8 adds yet another Kantian constraint on intuitions, i.e., that givenness is not sufficient for presence to consciousness. This will turn the table against the naïve realist reading of intuitions which does not seem to be able to allow for an object to be given in an intuition without its being present to the subject's consciousness. Finally, in Sect. 9, I will end with few concluding remarks.

I need not emphasize that, in this paper, I am not defending any representationalist view of the nature of empirical intuitions. As a matter of fact, I do not know if any of the standard theories of perception could capture different aspects of Kant's theory of empirical intuitions consistently. Rather, my goal mainly is to show that even if it turns out that Kant is committed to the a-e constraints, contrary to what his naive realist interpreters have been telling us, that neither forces him to reject a representationalist view of intuitions nor presses him to accept a naïve realist view of intuitions. ${ }^{1}$ The main thesis of this paper is that some naïve realist readers of Kant have attributed to him certain views on grounds that do not justify such attributions. More specifically, my arguments (i) will disarm the specific attacks against representationalist accounts of intuitions ${ }^{2}$ (ii) undercut the alleged superiority of the naïve realist reading of intuitions as the only savior of Transcendental Idealism from the perpetual threat of phenomenalism, ${ }^{3}$ (iii) show that empirical intuitions could not be given a naïve realist account after all, and finally, (iv) provide the representationalist readers of Kant with various ways of modeling empirical intuitions in representational terms which also satisfy the a-e constraints.

\section{Two preliminaries}

\subsection{Contemporary philosophy of perception}

There is something it is like for one to have a visual experience, say, of a red tomato. I'll call the properties that constitute what it is like for $\mathrm{S}$ to have a certain experience $e$, the phenomenal properties. According to the representationalist accounts of perceptual experience, phenomenal properties (of a subject) are identical to (or supervene on) some (of his) representational properties-i.e., the properties of representing certain contents (in certain ways). ${ }^{4}$ For the sake of simplicity, I mostly work with a version

\footnotetext{
1 Allais (2015, 2017), Gomes (2017), Hanna (2001) and McLear (2016, 2017), among others, argue for a naïve realist interpretation of Kant.

2 See, e.g., McLear (2016).

3 See, e.g., Allais (2015).

4 Chalmers (2004). I will not be concerned with how the relevant representational properties have to be characterized, i.e., whether they could be specified merely in terms of certain pure contents, or certain
} 
of representationalism according to which phenomenal properties are identical with (some) representational properties. However, later on, the distinction between the two versions-i.e., the identity thesis and the supervenience one-will become crucially important.

Right now I am having a visual experience of a monitor in front of me. According to the representationalist, my visual phenomenal properties are identical to (some of) my representational properties. However, there seems to be nothing, at least on a common way of characterizing it, that prevents me from representing the same content in the absence of the objects and properties that are being represented as in front of me, i.e., the monitor and its properties. It seems that one could represent a certain content even if things are not as one represents them to be. I could believe that I am Saul Kripke while, as a matter of fact, I am not. In the same way, I could visually represent a pink elephant in front of me while there is no relevant pink elephant there. The representationalist seems to have an easy explanation for what is going on in such cases: one could represent thus and so even when things are not the way they are being represented. So, if the phenomenal properties of a subject are identical to some of his representational properties, and one could represent a certain content in the absence of what is being represented, then one could visually represent, say, a pink elephant, when there is no pink elephant in the relevant place, or anywhere for that matter.

Here is a more accurate way of putting this idea:

1. For $\mathrm{S}$ to have a certain (visual) phenomenal property is for $\mathrm{S}$ to represent a certain content.

2. S could represent any content in the absence of the represented objects and properties.

3. S could have any (visual) phenomenal property in the absence of the objects and properties (that the experience seems to be of).

Many people tend to think that it is possible to undergo a non-veridical experience which is phenomenally indistinguishable, for the subject, from a veridical one. Standard representationalists account for phenomenal indistinguishability of such pairs of experiences in terms of the identity of the phenomenal properties involved in the two experiences; some veridical and hallucinatory experiences could be phenomenally indistinguishable because they could be type-identical-i.e., of the same specific type. By being of the same specific type, I mean that they are two tokens of the same specific type of phenomenal experiences. We could type-individuate things such that any two things fall under the same type. However, there is a sense according to which type-individuation is explanatorily salient. In this sense, if two things fall under the same specific type, they will have the same explanatory power. For instance, if two token perceptual experiences have the same explanatory power it is in virtue of being tokens of the same specific type; and if a token belief and a token desire have different explanatory powers it is because they are of different specific types, although they are of the same non-specific types, e.g., mental state, representational state, etc.

Footnote 4 continued

contents represented in a certain way, etc. So, in the rest of the paper, only in order to make things simpler, I sometimes will drop the quantifier 'some'. 
According to standard representationalism, the best explanation for why a veridical perception of a red tomato and a hallucination as of a red tomato could be phenomenally indistinguishable is because the subjects of these experiences share some phenomenal properties; given that, for the representationalist, phenomenal properties are identical to, and are individuated in terms of, representational properties, the commonality is cashed out in terms of the representational properties that the subjects of the two experiences have in common.

Depending on how one specifies the contents that one represents in a veridical perception and a hallucination, one could give a more specific account of what the common factor is. For instance, some representationalists believe that in having a veridical visual experience of a red tomato, one represents the following existential proposition:

$$
\exists x\left(\operatorname{Red}_{(\mathrm{x})} \& \operatorname{Round}_{(\mathrm{x})}\right)
$$

Further assume that one has an account of the content of a phenomenally indistinguishable hallucination according to which the subject represents the following content:

$$
\exists \mathrm{x}\left(\operatorname{Red}_{(\mathrm{x})} \& \operatorname{Round}_{(\mathrm{x})}\right)
$$

It is not hard to see that the subjects of these two experiences share some of their representational properties. More accurately, there is some representational property-i.e., the property of representing

$$
\exists \mathrm{x}\left(\operatorname{Red}_{(\mathrm{x})} \& \operatorname{Round}_{(\mathrm{x})}\right)
$$

that the two subjects have in common. This will help the representationalist to give an account of why the two experiences could be phenomenally indistinguishable in terms of the phenomenal (and ultimately, the representational) properties that the subjects of these experiences have in common. ${ }^{5}$ The idea that subjects of indistinguishable veridical and non-veridical experiences share some underlying psychological factor is known as the common-factor thesis.

Of course different representationalists might have different views regarding the contents of veridical and non-veridical experiences which may not allow for such an easy treatment of phenomenal indistinguishability in terms of phenomenal identity. I will come back to this issue in Sect. 4.

Then one might wonder-given the above characterization of the contents of veridical and hallucinatory experiences-what the difference between having phenomenally indistinguishable veridical and non-veridical experiences is. Well, the representationalist might say, the difference lies outside the phenomenal properties, for instance, in the causal histories of the two experiences; one is appropriately related to a red tomato

\footnotetext{
5 Note that I am not presenting a full account of phenomenal indistinguishability. Rather, I am giving a sketch of how a representationalist could use the representational properties that the two subjects have in common in her ultimate account of phenomenal indistinguishability. A full account of phenomenal indistinguishability requires me to argue for a specific account of the contents of hallucination. Doing that is beyond the scope of this paper.
} 
in front of the subject while the other is not related to a relevant red tomato. ${ }^{6}$ But, such a representationalist argues, this does not need to be reflected in the contents and the phenomenal properties.

The naïve realist disagrees. ${ }^{7}$ She believes that phenomenal properties are constituted by the perceived objects and their properties. When $\mathrm{S}$ has a veridical visual experience of a red tomato, $S$ has the experience that she does just because her experience is (partially) constituted by the red tomato, its round shape, its red color, etc. ${ }^{8}$ Given that the naïve realist type-individuates phenomenal properties in terms of the objects and property instances that one is related to, one could not have the same specific type of experience when there is no red tomato in front of her, or when this tomato is replaced with another one even if the two are qualitatively indistinguishable for the subject.

But it seems like I could have a hallucinatory experience that is phenomenally indistinguishable from some veridical experience. How could the naïve realist explain this? Well, he might say, all we can say about phenomenally indistinguishable veridical and hallucinatory experiences is that they are subjectively indistinguishable in the sense that the subject is unable to distinguish the two through mere reflection. ${ }^{9}$ Or, alternatively, he could give an account of the phenomenal properties in the hallucinatory experiences in terms of some kind of representational content, relation to sense data, modification of the subject's mind, etc. Nevertheless, the naïve realist argues that phenomenal indistinguishability of different experiences could not be accounted for in terms of some shared underlying psychological state. Instead she offers a disjunctive account of the phenomenal properties according to which the phenomenal properties of a subject of an experience as of, say, a red tomato are either constituted by the real tomato and its properties or they only seem to be of a red tomato. The latter disjunct could be given a negative analysis in terms of the inability of the subject to distinguish veridical and hallucinatory experiences through mere reflection (negative disjunctivism), or it could be cashed out in terms of some sort of representational content, relation to sense-data, etc. (positive disjunctivism).

So far I have introduced two oppositions in the contemporary philosophy of perception, representationalism versus naïve realism, and the common factor view versus disjunctivism. While the representationalist believes that the phenomenal properties are some sort of representational properties, the naïve realist denies that. And while the common factor theorist thinks that the subjects of phenomenally indistinguishable experiences share some underlying psychological state/property, the disjunctivist denies that there is such an underlying state/property. Most representationalists defend a common-factor view of phenomenology 10 - while naïve realists are disjunctivists. ${ }^{11}$

\footnotetext{
6 Grice (1961).

7 I will use 'naïve realism' and 'relationalism' interchangeably.

8 Campbell (2002), Fish (2009) and Martin (2004).

9 Martin (2006).

10 Tye (1995), Dretske (1995), Chalmers (2004) and Siegel (2010).

11 Travis (2004), Martin (2004), Campbell (2002) and Fish (2009).
} 


\subsection{Kant's terminology}

According to Kant, cognition of empirical objects requires two distinct faculties. The faculty of sensibility through which objects are given to the subject, and the faculty of understanding which enables the subject to cognize the objects given by the sensibility. The former provides the subject with what Kant calls intuitions and the latter delivers concepts and judgments.

Objects are... given to us by means of sensibility, and it alone affords us intuitions; but they are thought through the understanding, and from it arise concepts. ${ }^{12}$ (A19/B33)

Kant's terminology is not exactly the same one that we use in contemporary philosophy literature, let alone recent philosophy of perception. However, some philosophers take Kant's 'empirical intuitions'-i.e., intuitions of empirical objects-to be, more or less, what we refer to as 'perceptions' or 'perceptual experiences'. ${ }^{13}$ If so, then there are passages in Kant which seem to have a naïve realist flavor. In those passages, Kant seems to be suggesting that empirical intuitions are object-dependent in a very strong sense according to which one could not have an intuition of an object when the object does not exist or is not present. Given what we have said so far, this seems to be naturally inviting a naïve realist interpretation of empirical intuitions.

Using 'intuition' and 'perception/perceptual experience' interchangeably is not entirely uncontroversial. ${ }^{14}$ For Kant, there are delicate distinctions between 'empirical intuition' and 'perception'. ${ }^{15}$ This will not affect my discussion here since I will only be concerned with 'empirical intuitions' rather than 'perceptions', 'apperceptions', or other kinds of representations that Kant discusses. I will be arguing that, pace naïve realist readers of Kant, there is nothing in Kant's use of the notion of 'empirical intuitions' that makes it impossible for them to be cashed out entirely in representational terms. I will come back to this issue in Sect. 8 .

\section{Object-dependency of (empirical) intuitions}

Kant believes that (empirical) objects are given through (empirical) intuitions. There are certain passages in the Critique of Pure Reason and the Prolegomena where Kant seems to be suggesting that intuitions are object-dependent in the sense that it is not possible for a subject to have an intuition of an object in the absence of the object itself.

For instance, in A19/B33 Kant says:

\footnotetext{
12 I will follow the Cambridge Edition of Kant's works (Cambridge: 1999, 2004, 2006).

13 McLear (2016) and Stephenson (2015). I will adopt this terminological convention and move back and forth between using 'intuition' and 'perception/perceptual experience' until $\S 8$ when I discuss their differences.

${ }^{14}$ For instance, at least according to one interpretation of Kant sensations (and possibly intuitions) are only theoretical terms. See: Sellars (1968).

15 For a discussion of the differences between what Kant means by 'intuition', 'perception'-and other related notions, most notably 'apperception'—see: Tolley (2017).
} 
[T]hat through which it [= cognition] relates immediately to them [= objects $]$, and at which all thought as a means is directed as an end, is intuition. This, however, takes place only insofar as the object is given to us. [...] Objects are therefore given to us by means of sensibility, and it alone affords us intuitions. (A19/B33)

[Intuition] is immediately related to the object and is singular. (A320/B377)

One might take these remarks to mean that intuitions are produced by the sensibility alone and that the sensibility requires the presence of an object in order to generate an intuition (of that object). And here is an often cited passage from the Prolegomena:

An intuition is a representation of the sort which would depend immediately on the presence of an object. It therefore seems impossible originally to intuit a priori, since then the intuition would have to occur without an object being present, either previously or now, to which it could refer, and so it could not be an intuition. (4: pp. 281-282)

Naïve realist interpreters of Kant have argued that the idea of object-dependent intuitions could be captured in terms of the following sufficiency thesis:

The Sufficiency Thesis: If S intuits object $O$ at time $t$, then $O$ exists at $t$ and is suitably related to $\mathrm{S} .^{16}$

If Kant really endorses the Sufficiency Thesis, it might turn out that he could not after all believe that empirical intuitions are representations. The reason is that it seems, at least at first glance, that one could represent any object as being a certain way in the absence of the object that one represents (see Sect. 2.1). So, if intuitions could not occur in the absence of their objects, then maybe intuitions are not representations in the sense used in the contemporary philosophy of perception.

There is some textual evidence in Kant's writings that, to some extent, supports the idea that Kant did not endorse the Sufficiency Thesis. ${ }^{17}$ At any rate, I do not have more evidence of the same sort from Kant's writings to add to those that have already been presented. Hence, I will not be dealing with such issues here. In what follows, however, for the sake of argument, I will grant the naïve realist readers of Kant that he endorsed the Sufficiency Thesis. I will argue, nevertheless, that even if we grant this much, that does not show that empirical intuitions have to be relational. It is still possible to consistently endorse the Sufficiency Thesis and hold that intuitions are representations. Then, in the rest of the paper, I will incorporate, step by step, the rest of the (a)-(e) constraints into a representational theory of empirical intuitions.

In the next two sections, I will first present versions of representationalism that satisfy the object-dependency-i.e., the Sufficiency Thesis-and the singularity constraints, then I will argue that these forms of representationalism respect the immediacy of intuitions as well.

\footnotetext{
16 McLear (2017: p. 89). Allais (2015, 2017), Hanna (2001, 2005), McLear (2016) and Watkins and Willaschek (2017) defend similar views.

17 Stephenson $(2015,2017)$ and Grüne (2017).
} 


\section{Intuitions as object-dependent representations}

I am going to argue that it is open to the representationalist to accept the Sufficiency Thesis. Here is how, roughly, such a version of representationalism could be formulated. The representationalist could accept that intuitions are strongly object-dependent or, as I put it above, having an intuition is sufficient for the presence of its object. Here is the resulting picture: in veridical perceptions we have intuitions that are objectdependent. If the object were not present, it would not be possible for the subject to have that intuition.

Why would a representationalist endorse such a view? People have defended such a view for, at least, two different reasons. (i) The representationalist could appeal to the object-dependent intuitions to explain the singular nature of veridical perceptions of particulars. There is a red tomato in front of me now. My perception of the tomato seems to be of this specific red tomato, not any other qualitatively identical tomato; even if, unbeknownst to me, one replaces this tomato with another, qualitatively identical, tomato, there still is a sense in which my perception of the second tomato is different from the first one: they are experiences of numerically different objects (and hence ground different singular thoughts). (ii) If one wishes to ground singular thoughts in perception, a natural way to go is to take perceptual experiences to be object-dependent and singular. When I have two experiences of two numerically distinct but qualitatively identical objects, my experiences ground different singular thoughts just because they are experiences that are constituted by different contents: one has a content that has the first tomato as a constituent and the other has a content with the second tomato as its constituent. That's why my perception of the first tomato could not put me in a position to form a singular thought of the second tomato, though they might be qualitatively indistinguishable for me. ${ }^{18}$

This form of representationalism could take perceptual contents to be, for instance, Russellian propositions that are constituted by objects, their properties, and relations. When I have a veridical perception of, say, Tomato ${ }_{1}$, I have that experience because I visually represent the following proposition:

$$
\left(\operatorname{Red}_{(\text {Tomato1 })} \& \operatorname{Round}_{(\text {Tomato1) }}\right)
$$

And when I have a veridical experience of Tomato 2 , which could be qualitatively identical with Tomato 1 , I visually represent the following content:

$$
\left(\operatorname{Red}_{(\text {Tomato2) }} \& \operatorname{Round}_{(\text {Tomato2) }}\right)
$$

The two intuitions are constituted by different contents, and since the representationalist individuates intuitions in terms of their contents, they are different intuitions. As you can see, such a content is object-dependent; if I were hallucinating a tomato in front of me, then there would not be an appropriate tomato to be part of the content

18 (i) and (ii) are conceptually independent and one might wish to endorse one without endorsing the other-regardless of how plausible these choices will be. In particular, one might think that Kant only accepts (i) but not (ii), at least explicitly. 
of my intuition; I would only represent a gappy content, where the object-place is not filled with a real object.

Alternatively, object-dependent contents could be formulated in terms of de re Fregean modes of presentation. The idea is that it is possible for one to represent the same set of objects and properties in different ways. Therefore, corresponding to a Russellian proposition, there could be different Fregean propositions that constitute the contents of one's experience. Again, being a de re mode of presentation guarantees that the Sufficiency Thesis is satisfied. ${ }^{19}$ In the case of a phenomenally indistinguishable hallucination, however, the mode of presentation fails to pick out an appropriate object.

Is an object-dependent form of representationalism a plausible view to have? Well, knowing that the devil is in the details, the answer will depend on the details. Objectdependent representationalism could come, at least, in two variants. The less plausible one, I believe, is a form of disjunctivism: if the phenomenal properties are taken to be identical to some sort of representational properties, then one might think that the phenomenal properties of subjects of qualitatively indistinguishable veridical and non-veridical experiences could not be identical. But given that all forms of naïve realism have to embrace disjunctivism, disjunctivist representationalism is, at worst, as plausible as naïve realism in being a disjunctivist view. Note that type-individuating phenomenal properties in terms of representational properties does not necessitate a common-factor view. As far as one has not specified the contents of veridical and nonveridical experiences the choice between disjunctivism and the common-factor view is left open. What matters for my purposes here is that even if one holds that empirical intuitions are object-dependent and singular, and moreover, takes the phenomenal properties of a subject and his representational properties to be identical, one does not necessarily need to give into naïve realism. ${ }^{20}$

The naïve realist reader of Kant might find this less than satisfactory. She might ask: 'Then how is the object-dependent representationalist reading of intuitions, sketched above, different from the naïve realist reading?' Well, there are important differences between the two. One might prefer a disjunctivist representationalism over naïve realism for things that have to do with one's metaphysical commitments. But one might also think that there are good reasons from perceptual psychology to the effect that perceptual experiences have to be representational. For instance, Tyler Burge has argued that having a perceptual experience requires the perceptual system to overcome the underdetermination of the stimuli. Doing this, according to him, is achieved through the constancy mechanisms whose operations require constructing represen-

\footnotetext{
19 Evans (1982) and McDowell (1984). Note that I am not suggesting that Evans and others understand 'object-dependency' in the way I have presented it here. (For one, it is not clear that Evans defends an object-dependent view of perceptual content. Moreover, his notion of object-dependency is significantly weaker than the one required by the Sufficiency Thesis. For instance, in what he calls 'recognition-based thoughts', one could have an information-based thought of an object that one has encountered before in the absence of the object as long as one possesses, among other things, a capacity to recognize the object. Having this capacity obviously does not require the presence of the object.) All I am claiming is that, it is open to the representationalist to adopt such a stronger notion of object-dependency.

20 McDowell (2010) has defended a disjunctivist representationalism. However McDowell's disjunctivism might be merely epistemological. For a discussion of whether epistemological disjunctivism could be held independently of metaphysical disjunctivism, see: Soteriou (2016, Ch. 5).
} 
tations from environmental stimuli. ${ }^{21}$ One might also favor this view over its naïve realist rivals because one might think that not only does the disjunctivist version of representationalism avoid the myth of the Given, but it also has serious anti-skeptical merits. ${ }^{22}$ Whether or not this view has such merits, it does not seem to be incoherent.

If disjunctivism sounds unattractive for whatever reason-for instance if one thinks that phenomenally indistinguishable experiences have to share some underlying psychological state-and at the same time one is committed to the Sufficiency Thesis, then no worries; a more plausible version of representationalism, in my opinion, is available. The representationalist reader of object-dependent empirical intuitions could be a common-factor representationalist, if she wishes to. Here is one way that this could be achieved: assume that the phenomenal properties of a subject are not identical to, but, only supervene on the representational properties that he has in common in having a veridical experience and its phenomenally indistinguishable hallucination. Such a view is still a common-factor view of phenomenal properties. Given that one, or the main, reason most people find naïve realism unattractive is its commitment to disjunctivism about phenomenology, they need not worry because a common-factor, object-dependent, representationalist reading of empirical intuitions is available. According to this view the subject of a veridical perception represents a content which is object-dependent; but phenomenal properties are not object-dependent and supervene on the representational properties that subjects share in a veridical perception and its qualitatively indistinguishable hallucination.

This does not mean that the stronger, identity version, of representationalism is not available. The phenomenal properties of the subjects of veridical and non-veridical experiences could be, respectively, identical to their representational properties in the veridical and non-veridical cases. Therefore, the phenomenal properties of the subject of the veridical experience have the elements that they share with the phenomenal properties of the subject of the indistinguishable hallucination. However, only when the experience is veridical the representational properties (and hence the phenomenal properties of the subject) involve singular elements. Still, the two experiences need not be subjectively distinguishable. Nevertheless, subjective indistinguishability does not need to entail that the subjects are phenomenally identical, though they could still share their non-singular phenomenal properties.

Here is one way to make sense of such a view. Assume that $\mathrm{S}$ veridically represents $O$ as being red and round. According to this view, S represents the following objectdependent content:

$$
\left(\operatorname{Red}_{(\mathrm{O})} \& \operatorname{Round}_{(\mathrm{O})}\right)
$$

In a qualitatively indistinguishable (hallucinatory) experience, $\mathrm{S}$ might represent the following content:

$$
\left(\operatorname{Red}_{\left(\mathrm{O}^{\prime}\right)} \& \operatorname{Round}_{\left(\mathrm{O}^{\prime}\right)}\right)
$$

\footnotetext{
21 Burge (2010).

22 McDowell (1982, 1986, 2008, 2010).
} 
According to the identity version of representationalism, the phenomenal properties of the subject of the veridical experience will be identical to his representational properties-i.e., the property of representing $\left(\operatorname{Red}_{(\mathrm{O})} \& \operatorname{Round}_{(\mathrm{O})}\right)$-while the phenomenal properties of the subject of the latter experience will be identical to the property of representing $\left(\operatorname{Red}_{\left(\mathrm{O}^{\prime}\right)} \& \operatorname{Round}_{\left(\mathrm{O}^{\prime}\right)}\right)$. Again, it is intuitively clear that there is some representational property that these two subjects share, i.e., the property of representing

$$
\lambda x\left(\operatorname{Red}_{(\mathrm{x})} \& \operatorname{Round}_{(\mathrm{x})}\right)
$$

The common factor theorist could appeal to the shared representational properties of the two subjects to account for the qualitative indistinguishability of the two experiences. After all, phenomenal properties of a subject are identical to her representational properties and the subjects share some of their representational properties and hence some of their phenomenal properties. At the same time there is good reason to believe that phenomenal indistinguishability does not entail phenomenal identity. One could have a series of visual experiences in which each two successive experiences are phenomenally indistinguishable while the non-successive experiences are phenomenally distinguishable. $^{23}$

In the rest of the paper I will work with these two common-factor versions of representationalism: a supervenience version and a stronger identity version.

\section{Intuitions as immediate representations}

So far this is what we have: a common-factor, object-dependent, representationalist theory of empirical intuitions according to which phenomenal properties (of a subject) are identical to or supervene on (his) representational properties; in the veridical case, the subject represents an object-dependent content, while in the hallucinatory case he represents a content that is object-independent; there are some representational properties that are shared in both cases which constitute the common-factor, in the identity version, or the base of the supervenience, in the supervenience version. Let's see if these two could also satisfy the immediacy constraint.

One might think that if for $\mathrm{S}$ to perceive $O$ is for $\mathrm{S}$ to represent $O$, then $\mathrm{S}$ 's perception could not be immediate. But one might also think that empirical intuitions are objectdependent and present their objects immediately. Therefore, one might conclude that empirical intuitions could not be representations.

$\mathrm{P} 1$. Intuitions present their objects immediately.

P2. Perceptual representations do not present their objects immediately.

C. Therefore, intuitions are different from perceptual representations.

I need to make it clear what 'immediacy' means in this context. In what follows, I will present different ways of understanding the immediacy of intuitions.

23 Johnston (2004) and Speaks (2009, 2015). Note that the naïve realist herself has to deny that phenomenal indistinguishability entails phenomenal identity. Therefore, dialectically speaking, she is not in a position to press the common factor theorist to accept such an assumption. 
The constitutive reading of 'immediacy'. One way of understanding the immediacy is in terms of the constitutive conditions of empirical intuitions. Kant could be interpreted as saying that an empirical intuition presents its object immediately only when it is constituted by its object, i.e., the constitution conditions of the intuition involve its object. In this sense:

in virtue of tokening intuition, $i, \mathrm{~S}$ represents its object, $O$, immediately only if $i$ is constituted by $O$.

I have not specified the notion of 'constitution' here. The desired notion of constitution needs to be such that intuitions that are constituted by their objects will also satisfy the Sufficiency Thesis. There does not seem to be any reason that the notion of constitution in play has to be stronger than that. Nevertheless, I have argued that the Sufficiency Thesis could be satisfied by object-dependent representations. Therefore, if this is the notion of immediacy that Kant is concerned with, then the representationalist could hold that the subject, in virtue of representing object-dependent contents, could represent objects immediately because object-dependent contents are constituted by their objects. Hence, the constitutive reading of 'immediacy' does not show that Kant's empirical intuitions are not representations.

The psychological reading of 'immediacy'. Kant might have a psychological reading of 'immediacy' in mind. According to this reading,

in virtue of tokening intuition $i, \mathrm{~S}$ represents $O$ immediately iff $\mathrm{S}$, in virtue of tokening $i$, represents $O$ but not via representing something else, say, $R$.

So, in the psychological sense of the term, $\mathrm{S}$ represents $O$ mediately if $\mathrm{S}$ represents $O$, but only via representing something else, say $R$, which in turn represents $O$. In such a case, S's representation of $O$ is mediated by S's representation of $R$. As I understand representationalism, the claim is that for $\mathrm{S}$ to perceptually represent $O$, is for $\mathrm{S}$ to immediately represent $O$. The representationalist does not (and need not) claim that the perceiver's representation of the perceived object is mediated by his representation of something else. Rather in perceiving $O$, the subject will be in a position to immediately represent $O .^{24}$

There is nothing in the notion of representation, as I understand it and as it is used by most representationalists, that prevents it from being immediate in the psychological sense. Representationalists-and non-representationalists, for that matter- do not deny that there are processes going in one's perceptual system that enable one to represent $O$. But those could be only the enabling conditions for representing $O$. These processes may not be representational in the relevant sense-i.e., they could not be attributed to the subject. Therefore, when $\mathrm{S}$ is in a perceptual state that represents $O$, there is nothing in the notion of representation that makes it impossible for the perceiver to immediately represent the perceived object.

The epistemological reading of 'immediacy'. By being 'immediate' one might think that Kant has an epistemological notion of immediacy in mind. We might formulate this reading in terms of an awareness relation between the subject and the intuited object. According to this reading,

${ }^{24}$ See: Dretske (1995) and Tye (1995, 2000). 
in virtue of tokening intuition $i, \mathrm{~S}$ represents $O$ immediately only if in virtue of tokening $i, \mathrm{~S}$ becomes directly aware of $O$.

Most representationalists believe that perceptual experience puts the subject in a position to have a direct awareness of the perceived object and its properties, i.e., his awareness of the object is not mediated by his awareness of an intermediary. But if there is no intermediary in this sense, one's awareness of the perceived object and its properties will be direct: it is not the case that the perceiver's awareness of the perceived object depends on, for instance, an inference on the part of the subject or an awareness of an intermediary between the perceiver and the perceived object and properties. Rather, by tokening an appropriate representation, one becomes directly aware of the perceived object and properties. ${ }^{25}$ However, it is not clear that empirical intuitions play such an epistemological role all by themselves. This does not mean that, for Kant, the subject's awareness of the perceived object has to be indirect or mediated. Rather, it means that having an intuition does not seem to be sufficient for such a direct awareness. I will come back to this issue in Sect. 8.

This takes me to another way of understanding 'immediacy' which we may call 'phenomenal immediacy'. One might think that by immediacy of empirical intuitions, Kant means that the phenomenal properties of the subject of an empirical intuition is 'constituted' by the perceived objects and properties in the sense that, for instance, the phenomenal property $\varphi$ is identical with some property $p$ possessed by the perceived object $O$. For example, when $\mathrm{S}$ has an intuition of $O$ in which $O \operatorname{looks} \operatorname{red}_{\mathrm{ph}}$ to $\mathrm{S}$, the property red $_{\mathrm{ph}}$ is 'one and the same' as the physical redness which is instantiated by $O$, at least in the veridical case. Lucy Allais and Colin McLear, among the relationalist readers of Kant, seem to be defending such a view.

[T] he qualitative features of perceptual experience are features of the objects perceived (particular instances of properties). (Allais 2015: p. 107)

The subject's environment constitutes the contours of her experience in the way, to use one contemporary philosopher's turn of phrase, a hillside constitutes the contours of the landscape of which it is part. (McLear 2016, p. 128)

Such a view is not unprecedented among representationalists. Some externalist representationalists seem to be defending a similar view. ${ }^{26}$ So, representationalists have already provided models of perceptual experience that could incorporate 'phenomenal immediacy'. These forms of representationalism arguably have to be disjunctivist about the phenomenal properties in veridical and non-veridical perceptual experiences.

I doubt that such a view could be plausible. ${ }^{27}$ However, I need not pursue this issue further here. The reason is that I tend to think that by 'immediacy', Kant could not mean 'phenomenal immediacy'. I will come back to this issue in Sect. 8.

Depending on how a representationalist characterizes the contents of intuitions, it might be relevant to talk about other kinds of 'immediacy' as well. Here is a possible model of empirical intuitions: empirical intuitions are de re modes of presentations and relate to objects in the world via semantic relations. At first glance, this model makes

\footnotetext{
${ }^{25}$ Harman (1990) and Tye (1995, §5.1).

26 Dretske (1995) and Tye (1995).

27 Chalmers $(2004, \S 2)$.
} 
the relation of the subject to the intuited objects and properties mediated by the veil of the Fregean senses. However, this model could satisfy the immediacy constraint, at least, as far as empirical intuitions' relations to their objects could be immediate in the context of Kant's Transcendental Idealism. Here is how: if one takes the de re Fregean senses to be analogues of the 'appearances', and their referents to be analogues of the 'things in themselves', then even in this model intuitions are still immediate in the relevant sense. ${ }^{28}$

Of course, a Fregean model, with different details, could lead to a picture in which the subject's access to the intuited objects (the appearances) is mediated; for instance, if in the Fregean model of empirical intuitions the Fregean senses are taken to be mediary representations that are the primary objects of awareness which in turn provide the subject's access to the 'appearances' (now understood as the referents of the Fregean senses), then the the Fregean senses are immediately given to the subject, however, the appearances (as the referents of these representations) have been given only mediately.

Now, depending on what are taken to be the analogues of Kant's 'appearances' and 'things in themselves', the relation of empirical intuitions and their objects might turn out to be mediate or immediate in each of these representational models. But, as I have been arguing, I do not see any reason to think that a representational theory of empirical intuitions as such could not accommodate the immediacy of intuitions.

\section{Propositional: to be or not to be}

So far I have argued that a version of representationalism with singular content could satisfy the object-dependency, singularity, and immediacy constraints. But we are not done yet. Kant tells us that intuitions have to meet other conditions as well. In particular, some have argued that Kant seems to be thinking that intuitions are not truth-apt. At A293/B350, Kant says:

[I]t is correctly said that the senses do not err; yet not because they always judge correctly, but because they do not judge at all. Hence truth, as much as error, and thus also illusion as leading to the latter, are to be found only in judgments. ${ }^{29}$

One might interpret Kant such that by "the senses do not err", he means that "intuitions do not err". ${ }^{30}$ Let's, for the sake of argument, grant this reading. If so, then Kant rules out the possibility of one kind of error with regard to the senses,- -i.e., empirical intuitions - the kind of error that judgments are liable to; intuitions could not be false, since truth and falsity are properties of judgments and intuitions do not involve judgments. Propositional contents, however, seem to have truth conditions. This might sound like a problem for a propositional model of intuitions.

There are multiple routes available to the representationalist who wants to accommodate this new constraint. The least revisionary way would be to appeal to the following Cartesian wisdom. In the Fourth Meditation, having already proved the

\footnotetext{
28 This is the model that is developed and defended by Tolley (forthcoming).

29 Also see: (Anthropology §11 7: p. 146).

30 McLear (2016, §4.1) and Gomes (2017).
} 
existence of his self and God despite the deceptions of his senses, Descartes embarks on the task of finding out what the sources of error are. He ultimately tells us, and this should not have been news to Kant, that we err not when we do no perceive the truth, rather only when we go on and form judgments.

If I simply refrain from making a judgment in cases where I do not perceive the truth with sufficient clarity and distinctness, then it is clear that I am behaving correctly and avoiding error. ${ }^{31}$

Descartes seems to be suggesting that perceptions that are not clear and distinct still do not yield error unless they are accompanied by acts of endorsement. Building on this insight, one might, quite plausibly, hold that there is a difference between taking the attitude of perceptually experiencing/intuiting towards a content on the one hand, and taking the attitude of judging towards that same content. The attitude of experiencing/intuiting, one might argue, lacks the assertoric force that the attitude of judging possesses and makes it prone to error. After all, the mere possession of propositional content does not entail truth-aptness; just by assigning propositional contents to desires, hopes, etc., one will not be committed to their truth-aptness. ${ }^{32}$

A further worry about assigning propositional contents to empirical intuitions might come from the different roles that Kant attaches to the sensibility and the understanding in his account of cognition. For although Kant thinks that the sensibility delivers intuitions, however,

[T] he combination (conjunctio) of a manifold in general can never come to us through the senses, and therefore cannot already be contained in the pure form of sensible intuition [...] all combination [...] is an action of the understanding, which we would designate with the general title synthesis.(B129/130)

Every form of combination is an act of the understanding. One might also think that propositions require combination, since "such content must have a special kind of order relating its elements, and this order can only come about through the cognitive activity of a spontaneous intellect." 33 But intuitions are products of the sensibility which is independent from (and prior to) the understanding. Therefore, intuitions could not have propositional contents. ${ }^{34}$

In response the representationalist could simply adopt a possible world view of propositional content. ${ }^{35}$ But this is not mandatory. The reason is that it seems to me that this worry is due to a misunderstanding regarding the nature of propositions. It is true that a propositional content has some structure. However, the components of a propositions are not (and could not be) combined in the way that the understanding combines or synthesizes, i.e., by "uniting representations in a consciousness". ${ }^{36}$ Russellian propositions, for instance, are complex entities composed of worldly objects,

\footnotetext{
31 Descartes (1641/1996, p. 41).

32 Also see: Siegel (2013) and Travis (2013).

33 McLear (2016, p. 111).

34 See: the 'argument from combination' in McLear (2016, §4.2).

35 Stalnaker (1976). Then the common-factor has to be spelled out in terms of some shared function.

36 Prolegomena (\$22 4: p. 304).
} 
their properties and relations. These do not seem to be the right sorts of things that the understanding could synthesize to form judgments. The unity of a Russellian proposition is not a matter of the understanding having combined its components.

On the other hand, even in the case of Fregean propositions whose components are modes of presentations of objects and properties, as long as the idea of nonconceptual content is coherent, their unity could not be a matter of a synthesis by the understanding, unless Kant requires any unity, whether or not it has to do with concepts and representations, to be a matter of a synthesis by the understanding. Fregean modes of presentation are not mental entities. They are rather supposed to be the entities that are being represented. The unity of a proposition is a relation among the entities that are being represented-objects, properties, modes of presentations, etc.-while the combination/synthesis that the understanding is concerned with is a matter of a relation between representations-i.e., in this context, concepts. These are relations among entities from different categories and thus different relations.

Nonetheless, even signing up for a propositional content is not mandatory and as a matter of fact, it may not be the most plausible view of content to hold either. For instance, one might argue that perceptual content has to involve a singular element along with an attributive element without being propositional. ${ }^{37}$ The singular element still guarantees that the (a)-(c) constraints are satisfied while the non-propositional structure satisfies (d), i.e., the non-truth-aptness. This sort of content need not be conceptual either, as most representationalists agree. The non-conceptual nature of content (and thus intuitions) respects the autonomy of the sensibility from the understanding, if one wishes to be committed to their independence.

\section{Proof of the possibility of cognized objects}

Let's now turn to an argument against the representationalist readings of intuitions that I have developed so far. Colin McLear (2016) has presented three arguments against representationalist theories of intuitions. His first two arguments-what he calls 'the argument from deception' and 'the argument from combination'-if sound, work only against propositional, truth-apt theories of content. We already discussed these in Sect. 6. However, he has a third argument, 'the argument from Modality', which he believes applies to all forms of representationalism, or 'the Content View' as he puts it. ${ }^{38}$ His argument is based on the following passage from the B Introduction of the Critique, where Kant tells us that:

To cognize an object, it is required that I be able to prove its possibility (whether by the testimony of experience from its actuality or a priori through reason). But I can think whatever I like, as long as I do not contradict myself, i.e., as long as my concept is a possible thought, even if I cannot give any assurance whether or not there is a corresponding object somewhere within the sum total of all possibilities. But in order to ascribe objective validity to such a concept (real possibility, for the first sort of possibility was merely logical) something more

\footnotetext{
37 Burge (2005, 2010).

38 McLear's argument is inspired by some insights taken from Chignell (2011).
} 
is required. This "more," however, need not be sought in theoretical sources of cognition; it may also lie in practical ones. (Bxxvi-fn)

McLear believes that the task of providing a proof of the real possibility of the cognized objects has to be done by the intuitions. ${ }^{39}$ As I have been arguing above, intuitions could be constituted by singular elements. This will do the task of providing a 'proof of the real possibility of the cognized object'. McLear agrees. Nonetheless, he is not ultimately convinced because he believes that if we do so, "we lose the Content View's neat explanation of illusion and hallucination." 40 By this he means that we will no longer have an explanation of the phenomenal indistinguishability of veridical and non-veridical experiences in terms of a common underlying factor.

I have been arguing that this need not be the case. The representationalist need not think that the phenomenal properties of a subject are identical to his representational properties. Then, here is a neat explanation of phenomenal indistinguishability for the content view: the phenomenal properties of a subject supervene on the representational properties that are shared by the subjects in a veridical experience and its hallucinatory indistinguishable experience. This could be cashed out in different ways, for instance, via an appropriate $\lambda$-abstraction on the singular elements of the object-dependent contents (see Sect. 4). In other words, the contents of these two kinds of experiences could be disjunctive: in the veridical case, the content is constituted by the perceived objects and properties; in the non-veridical case, however, the content is object-independent. But the phenomenal properties of the subjects of the two experience are type-identical because phenomenal properties are invariant between a veridical experience of, say, a red tomato and its indistinguishable hallucinatory experience. So, we still have a common-factor view of phenomenal properties in the context of an object-dependent representational theory of intuitions.

Also, as I mentioned before, the common-factor theorist need not think that phenomenally indistinguishable veridical and non-veridical experiences are phenomenally identical. She could argue that although phenomenal indistinguishability indicates that the two subjects share some of their representational (and thus some of their phenomenal) properties, that does not show that the two subjects have to be phenomenally identical. Therefore, the common-factor theorist could still hold the stronger view according to which phenomenal properties of a subject are identical to his representational properties.

The opponent might worry that the common-factor delivered by this account is not common-factor enough. She might point out that the common-factor was supposed to provide an account of the indiscernibility of veridical and non-veridical experiences entirely in terms of some shared phenomenal properties, i.e., the identity of the phenomenal properties. However, if subjects of indiscernible experiences could still be phenomenally distinct, then the phenomenal properties shared by the two subjects will not be sufficient as a ground for their indiscernibility. So, one might object that the version of representationalism that we are concerned with has, after all, failed to give a "neat explanation of illusion and hallucination".

\footnotetext{
39 For a different interpretation of this passage, see: Tolley (2017, fn. 42, 43).

40 McLear (2016). Note that showing that intuitions could not be given a common-factor representationalist account is significantly weaker than showing that intuitions are not representations.
} 
It is true that this version of representationalism could not give an account of the indiscernibility of veridical and non-veridical experiences entirely in terms of the shared phenomenal properties. So, if one chooses to call the view that two phenomenally indiscernible experiences are phenomenally identical, and only this view, a 'common-factor' view, then the identity version of representationalism presented above is not a common-factor view. However, that is a verbal issue. Nevertheless, there is a philosophically interesting issue of whether phenomenally indiscernible experiences share all or part of their phenomenal natures or whether they must be given only a disjunctive account. The representationalist in question is in a position to accept that phenomenal indistinguishability could partially be a matter of the subjects of the two experiences having some of their phenomenal properties in common. At the same time it is plausible, on independent grounds, that to require that the subject be in a position to distinguish all changes in his representational or phenomenal properties is too demanding. ${ }^{41}$

\section{Givenness without presence}

So far my project has been that of showing that the naïve realist front has not given us a reason for why intuitions have to be relational and not mere representations. Now, let's turn the table. Not only have not they presented any argument against a representational account of intuitions, but, quite contrary, there is good reason to adopt such a view and reject a relationalist account of intuitions. In this section I will present such an argument based on another Kantian constraint on intuitions, i.e., that givenness does not require presence to consciousness.

In a section of Anthropology from a Pragmatic Point of View, entitled 'On the representations that we have without being conscious of them', Kant says

The field of sensuous intuitions and sensations of which we are not conscious, even though we can undoubtedly conclude that we have them; that is, obscure representations in the human being (and thus also in animals), is immense. (Anthropology, 7:135)

This passage seems to suggest that sensible intuition is not necessarily conscious, it could be had unconsciously as well. Kant seems to be thinking that one can consciously represent an object in intuition as a whole without being in a position to consciously represent its parts. For instance, I could see a man who is far away without seeing his eyes, or nose, etc. In such a case, Kant does not want to say that I do not represent the parts-e.g., eyes, nose, etc.-in my manifold of intuition, because:

If I wanted to maintain that I do not at all have the representation of him in my intuition because I am not conscious of perceiving these parts of his head (and so also the remaining parts of this human being), then I would also not be able to say that I see a human being. (Anthropology, 7:135)

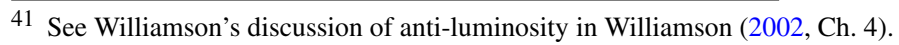


Instead, Kant goes on to suggest that: "[t]he field of sensuous intuitions and sensations of which we are not conscious [...] is immense."

Here is how I understand these passages; Kant seems to be suggesting that to have an intuition of an object as a whole, one has to have intuitions of the object's parts. But there are case in which one does not seem to represents some parts of an object in the manifold of intuitions, despite representing the object as a whole. This does not seem to be right, given that Kant believes that the representation of a whole in intuition in the absence of the representations of its parts is not possible. Kant's way out of this conundrum is that the correct description of the situation in which one represents an object as a whole in the manifold of intuitions but does not seem to represent its part is the following: while the subject is consciously representing the whole object in intuition, she is only unconsciously representing its parts in intuition. ${ }^{42}$

We need to make room for unconscious representation of the manifold of intuitions in our representational picture of intuitions. In order to bring unconscious intuitions under a representational account of intuitions I need to adjust the base of the supervenience relation and revise the identity claim; the phenomenal properties of a subject could not simply supervene on (or be identical to) his representational properties; one could represent a certain content consciously or unconsciously. Rather, in the updated version, phenomenal properties have to supervene on (or be identical to) the property of representing a certain content that meets certain other conditions such that the intuited contents plus those conditions fix the phenomenal properties of the subject. The additional conditions need to be filled out with those that Kant believes, when added to an intuition, the resulting state will necessarily be conscious, whatever they might be. These could involve, for instance, availability to the higher cognitive systems, having a specific kind of content, etc. ${ }^{43}$

The naïve realist reader of Kant needs to tell us how it is possible for empirical intuitions to be relational and be conscious or unconscious. While the representationalist could adjust his view such that it allows for both conscious and unconscious intuitions, it is not clear that the naïve realist has enough resources to do the same. ${ }^{44}$ Relationalism is usually presented as a theory of perceptual 'experience', i.e., conscious perception. Relationalists think that the nature of perceptual experience is exhausted in terms of an 'acquaintance relation' between the subject and the perceived object and its properties. The relationalist reader of Kant thinks that this gives an accurate account of the nature of 'empirical intuitions'. Therefore, on this account,

for $\mathrm{S}$ to have an empirical intuition of $O$ is for $\mathrm{S}$ to be acquainted with $O{ }^{45}$

\footnotetext{
42 For a defense of 'unconscious intuitions', see: Tolley (2017).

43 Tye (1995: §5.2).

44 Stephenson $(2017,106)$, citing the discussed passage from the Anthropology, mentions that "One apparent problem for the relational view, which ties intuitions essentially to consciousness, is that Kant sometimes seems to allow for unconscious intuitions... The representational view can accommodate this more easily than the relational view".
} 
At the same time, relationalists, following Russell, understand the notion of 'acquaintance' such that for $\mathrm{S}$ to be acquainted with $O$ is for $O$ to be presented to S's consciousness. ${ }^{46}$

The notion of acquaintance was cashed out in terms of the subject's perceptual experience being partially constituted by her environment. It is in virtue of this constitutive relationship that perceptual experience can fulfil its role in giving objects to consciousness. ${ }^{47}$ (McLear 2016)

(Note that McLear uses 'perceptual experience' and 'empirical intuition' interchangeably). According to the relationalist reader of Kant, for $\mathrm{S}$ to have an intuition of $O$ is for $\mathrm{S}$ to be acquainted with $O$ and acquaintance with $O$ is sufficient for $O$ to be present to $S$ 's consciousness. If the acquaintance relation is sufficient for the intuition to be conscious, then given that having an intuition of $O$ is to be acquainted with $O$, this account does not seem to allow for unconscious intuitions.

What the naïve realist needs to do is to replace the 'acquaintance relation' with another relation $R$ such that it satisfies all the constraints on empirical intuitions; moreover, from ' $\mathrm{S}$ is $R$-related to $O$ ' it does not follow that $O$ is present to S's consciousness. This does not seem to be a trivial task. At least it is not very clear how a relation $R$ could satisfy all these roles and obtain consciously and unconsciously.

The naïve realist might argue that in the passages that Kant discusses unconscious intuitions, by 'unconscious' he refers to lack of some sort of higher-order thought rather than a basic acquaintance. So, by allowing for the possibility of unconscious intuitions, Kant allows that the intuiting subject could lack higher-order thoughts about the intuited objects. But acquaintance does not require higher-order thoughts.

This sounds like a plausible view to me. But I believe, at the end of the day, it does not help the acquaintance view of empirical intuitions. The reason is that in the passages that Kant talks about unconscious intuitions he does not seem to be discussing a defect in the subject that denies him the ability to form higher-order thoughts. Kant does not seem to be suggesting that the subject lacks the ability to form thoughts or lacks the requisite conceptual resources. Rather, what prevents the subject from having higher-order thoughts seems to be exactly what acquaintance would provide, namely a basic personal-level cognitive access to the intuited object. It is not clear how one could be acquainted with an object but lack the right kind of cognitive access that, provided that one has the requisite concepts and the ability to form higher-order thoughts, would afford one higher-order thoughts.

One might dispute the details of the example presented by Kant or my understanding of the case. However, the details of this case are dispensable. We can run the same argument against the acquaintance view of intuitions without relying on the specifics of this case. Kant seems to be relying on a general principle regarding the relation between an intuition of an object and intuitions of its parts. Immediately after the passage quoted before, Kant goes on to say:

\footnotetext{
45 See: Allais (2017: p. 32), Allais (2015: pp. 11, 147, 148, 155), McLear (2016, §5).

46 Russell (1910). Also see: Allais (2015, pp. 11, 159, 302-303), McLear (2016).

47 "I argue that Kantian intuitions are representations that give us acquaintance with objects, and that since he thinks cognition requires intuition, he thinks our cognition is limited to that with which we can have acquaintance: what can be presented to us in a conscious experience". (Allais (2015: p. 11). My emphasis).
} 
[I]f I wanted to maintain that I do not have the representation of him in my intuition because I am not conscious of perceiving these parts of his head (and so also the remaining parts of this human being), then I would also not be able to say that I see a human being, since the representation of the whole (of the head or of the human being) is composed of these partial ideas. (Anthropology, 7:135. My emphasis.)

This seems to suggest that Kant is committed to the following principle:

(I) if $\mathrm{S}$ intuits $O$, then $\mathrm{S}$ intuits $O$ 's parts.

But it is also plausible that it is possible for $\mathrm{S}$ to see an object $O$ without seeing (some of) its parts. And, from that and (I) it follows that it is possible for $\mathrm{S}$ to have an intuition of something without seeing it. At the same time, not seeing the object's parts (quite plausibly) need not be due to a deficiency on the part of the intuiting subject, or his not attending to the object parts. After all, we could always have a normal subject attend to a man far away without him being able to see the man's eyes, or nose, etc.

Given the arguments of this section, there is good reason to believe that Kant is committed to the view that having an intuition of $O$ is not sufficient for the subject to be acquainted with $O$. In other words, $O$ could be given in an intuition $i$ without its being present to one's consciousness even if, according to the Sufficiency Thesis, having $i$ requires the presence of $O$.

\section{Conclusion}

I have argued that even if Kant thinks of empirical intuitions as (a) singular, (b) object-dependent, and (c) immediate 'presentations' which (d) are not truth-apt, and (e) provide the subject with a proof of the possibility of the cognized object, empirical intuitions could still be representations. Of course, (i) it is not clear that the representationalist reader of Kant needs to satisfy all the a-e constraints; I granted the naïve realist the a-e constraints only to show that those constraints do not rule out all representationalist readings of empirical intuitions; moreover, (ii) the passages that are appealed to in support of the a-e constraints have other less-hostile-to-the-representationalist readings as well. Nevertheless, by now it should be clear that the naïve realist readers of Kant have not given us any reason for why empirical intuitions could not be mere representations. Moreover, the preached virtue of a naïve realist account of empirical intuitions, i.e., saving Transcendental Idealism from falling into the abyss of phenomenalism, could perfectly be obtained by the representationalist.

At the same time there are other constraints on the nature of empirical intuitions that may not be treated so well under naïve realist assumptions. In particular, Kant seems to allow for the manifold of intuitions to be represented either consciously or unconsciously. Satisfying this constraint requires an appropriate relation $R$ that could satisfy the a-e conditions and is such that one could be $R$-related to $O$ either consciously or unconsciously. However, I have not shown that Kant is committed to a representationalist view of intuitions. One might ultimately find some passages that rule out the possibility of any representationalist view of empirical intuitions; or, at 
the end of the day, it could turn out that "there is no systematically presented 'theory of perception' in our contemporary sense in the Critique, which suggests that there is a clear sense in which it is problematic to argue either that Kant did or did not hold one of these theories." 48

Having said all that, I believe that some of the constraints in the a-e list should be rejected. Specifically, I believe that the strong object-dependency of intuitions captured in terms of the Sufficiency Thesis is not, philosophically speaking, a very plausible view to hold; imposing such a constraint on the nature of empirical intuitions fatally damages the explanatory power of intuitions elsewhere in Kant's account of empirical cognitions. $^{49}$

Acknowledgements This paper has benefited from comments by (and/or discussions with) Lucy Allais, Jonathan Cohen, Matthew Fulkerson, Farid Masrour, Clinton Tolley, Brian Tracz, and Eric Watkins. I am especially grateful to Jonathan Cohen, Clinton Tolley, and an anonymous referee for multiple rounds of detailed comments.

\section{References}

Allais, L. (2015). Manifest reality: Kant's idealism and his realism. Oxford: OUP Oxford.

Allais, L. (2017). Synthesis and binding. In Andrew Stephenson \& Anil Gomes (Eds.), Kant and the philosophy of mind (pp. 25-45). Oxford: Oxford University Press.

Burge, T. (2005). Disjunctivism and perceptual psychology. Philosophical Topics, 33(1), 1-78.

Burge, T. (2010). Origins of objectivity. Oxford: Oxford University Press.

Campbell, J. (2002). Reference and consciousness. Oxford: Oxford University Press.

Chalmers, D. J. (2004). The representational character of experience. In B. Leiter (Ed.), The future for philosophy (pp. 153-181). Oxford: Oxford University Press.

Chignell, A. (2011). Real repugnance and our ignorance of things-in-themselves: A Lockean problem in Kant and Hegel. Internationales Jahrbuch des Deutschen Idealismus, 7, 135-159.

Descartes, R. (1641/1996). René Descartes: Meditations on first philosophy: With selections from the objections and replies. Cambridge University Press.

Dretske, F. (1995). Naturalizing the mind. Cambridge, MA: MIT Press.

Evans, G. (1982). The varieties of reference. Oxford: Oxford University Press.

Fish, W. (2009). Perception, hallucination, and illusion. New York: Oxford University Press.

Gomes, A. (2017). Naïve realism in Kantian phrase. Mind, 126(502), 529-578.

Grice, H. P. (1961). The causal theory of perception. Proceedings of the Aristotelian Society, 35, 121-153.

Grüne, S. (2017). Are Kantian intuitions object-dependent? In Andrew Stephenson \& Anil Gomes (Eds.), Kant and the philosophy of mind (pp. 67-85). Oxford: Oxford University Press.

Hanna, R. (2001). Kant and the foundations of analytic philosophy. Oxford: OUP.

Hanna, R. (2005). Kant and non-conceptual content. European Journal of Philosophy, 13(2), 247-290.

Harman, G. (1990). The intrinsic quality of experience. Philosophical Perspectives, 4, 31-35.

Johnston, M. (2004). The obscure object of hallucination. Philosophical Studies, 103, 113-183.

Kant, I. (1999). Critique of pure reason. Cambridge: Cambridge University Press.

Kant, I. (2004). Prolegomena to any future metaphysics: That will be able to come forward as science. With selections from the critique of pure reason. Cambridge: Cambridge University Press.

Kant, I. (2006). Anthropology from a pragmatic point of view. Cambridge: Cambridge University Press.

Martin, M. G. F. (2004). The limits of self-awareness. Philosophical Studies, 120, 37-89.

Martin, M. G. F. (2006). On being alienated. In T. S. Gendler \& J. Hawthorne (Eds.), Perceptual experience (pp. 354-410). Oxford: Oxford University Press.

McDowell, J. (1982). Criteria, defeasibility and knowledge. Proceedings of the British Academy, 68, $455-479$.

48 Allais (2015, p. 105).
49 Shahmoradi (draft). 
McDowell, J. (1984). De re senses. The Philosophical Quarterly, 34(136), 283-294.

McDowell, J. (1986). Singular thought and the extent of inner space. In P. Pettit \& J. McDowell (Eds.), Subject, thought and context (pp. 137-168). Oxford: Clarendon Press.

McDowell, J. (2008). The disjunctive conception of experience as material for a transcendental argument. In Fiona Macpherson \& Adrian Haddock (Eds.), Disjunctivism: Perception, action, knowledge (pp. 376-389). Oxford: Oxford University Press.

McDowell, J. (2010). Tyler Burge on disjunctivism. Philosophical Explorations, 13(3), 243-255.

McLear, C. (2016). Kant on perceptual content. Mind, 125(497), 95-144.

McLear, C. (2017). Intuition and presence. In Andrew Stephenson \& Anil Gomes (Eds.), Kant and the philosophy of mind (pp. 86-103). Oxford: Oxford University Press.

Russell, B. (1910). Knowledge by acquaintance and knowledge by description. Proceedings of the Aristotelian Society, 11, 108-128.

Sellars, W. (1968). Science and metaphysics: Variations on Kantian themes. London: Routledge \& Kegan Paul.

Shahmoradi, A. (draft). Object-dependency of Intuitions vs. intuition-dependency of cognitions.

Siegel, S. (2010). The contents of visual experience. New York: Oxford University Press.

Siegel, S. (2013). Replies to Campbell, Prinz, and Travis. Philosophical Studies, 163(3), 847-865.

Soteriou, M. (2016). Disjunctivism. London: Routledge.

Speaks, J. (2009). Transparency, intentionalism, and the nature of perceptual content. Philosophy and Phenomenological Research, 79(3), 539-573.

Speaks, J. (2015). The phenomenal and the representational. Oxford: OUP Oxford.

Stalnaker, R. C. (1976). Possible worlds. Noûs, 10, 65-75.

Stephenson, A. (2015). Kant on the object-dependence of intuition and hallucination. The Philosophical Quarterly, 65(260), 486-508.

Stephenson, A. (2017). Imagination and inner intuition. In A. Gomes \& A. Stephenson (Eds.), Kant and the philosophy of mind: Perception, reason, and the self (pp. 104-123). Oxford: Oxford University Press.

Tolley, C. (2017). Kant on the place of cognition in the progression of our representations. Synthese. https:// doi.org/10.1007/s11229-017-1625-3.

Tolley, C. (forthcoming). Kant's appearances as object-dependent senses. In N. Stang \& K. Schafer (Eds.), On the sensible and intelligible worlds. Oxford: Oxford University Press.

Travis, C. (2004). The silence of the senses. Mind, 113(449), 57-94.

Travis, C. (2013). Susanna Siegel, the contents of visual experience. Philosophical Studies, 163(3), 837-846.

Tye, M. (1995). Ten problems of consciousness: A representational theory of the phenomenal mind. Cambridge: MIT Press.

Watkins, E., \& Willaschek, M. (2017). Kant's account of cognition. Journal of the History of Philosophy, $55(1), 83-112$.

Williamson, T. (2002). Knowledge and its limits. Oxford University Press.

Publisher's Note Springer Nature remains neutral with regard to jurisdictional claims in published maps and institutional affiliations. 